\title{
Impact of obesity on complications, infection, and patient-reported outcomes in adult spinal deformity surgery
}

\author{
Alex Soroceanu, MD, MPH, ${ }^{1}$ Douglas C. Burton, MD, ${ }^{2}$ Bassel Georges Diebo, MD, ${ }^{1}$ \\ Justin S. Smith, MD, PhD, ${ }^{3}$ Richard Hostin, MD, ${ }^{4}$ Christopher I. Shaffrey, MD, ${ }^{3}$ \\ Oheneba Boachie-Adjei, MD, ${ }^{5}$ Gregory M. Mundis Jr., MD, ${ }^{6}$ Christopher Ames, MD, ${ }^{7}$ \\ Thomas J. Errico, MD, ${ }^{1}$ Shay Bess, MD, ${ }^{8}$ Munish C. Gupta, MD, ${ }^{9}$ Robert A. Hart, MD, ${ }^{10}$ \\ Frank J. Schwab, MD, ${ }^{1}$ Virginie Lafage, MD, ${ }^{1}$ and the International Spine Study Group
}

\begin{abstract}
${ }^{1}$ Orthopaedic Surgery, NYU Hospital for Joint Diseases, New York, New York; ${ }^{2}$ Orthopaedic Surgery, University of Kansas Medical Center, Kansas City, Kansas; ${ }^{3}$ Neurosurgery, University of Virginia Medical Center, Charlottesville, Virginia; ${ }^{4}$ Orthopaedic Surgery, Baylor Scoliosis Center, Plano, Texas; ${ }^{5}$ Orthopaedic Surgery, Hospital for Special Surgery, New York, New York; ${ }^{6}$ San Diego Center for Spinal Disorders, La Jolla, California; ${ }^{7}$ Orthopaedic Surgery, University of California San Francisco, California; ${ }^{8}$ Orthopaedic Surgery, Rocky Mountain Hospital for Children, Denver, Colorado; ${ }^{\circ}$ Orthopaedic Surgery, University of California Davis, Sacramento, California; and ${ }^{10}$ Orthopaedic Surgery, Oregon Health \& Science University, Portland, Oregon
\end{abstract}

OBJECT Adult spinal deformity (ASD) surgery is known for its high complication rate. This study examined the impact of obesity on complication rates, infection, and patient-reported outcomes in patients undergoing surgery for ASD.

METHODS This study was a retrospective review of a multicenter prospective database of patients with ASD who were treated surgically. Patients with available 2-year follow-up data were included. Obesity was defined as having a body mass index $(\mathrm{BMI}) \geq 30 \mathrm{~kg} / \mathrm{m}^{2}$. Data collected included complications (total, minor, major, implant-related, radiographic, infection, revision surgery, and neurological injury), estimated blood loss (EBL), operating room (OR) time, length of stay (LOS), and patient-reported questionnaires (Oswestry Disability Index [ODI], Short Form-36 [SF-36], and Scoliosis Research Society [SRS]) at baseline and at 6 weeks, 1 year, and 2 years postoperatively. The impact of obesity was studied using multivariate modeling, accounting for confounders.

RESULTS Of 241 patients who satisfied inclusion criteria, 175 patients were nonobese and 66 were obese. Regression models showed that obese patients had a higher overall incidence of major complications $($ IRR 1.54, $p=0.02)$ and wound infections (odds ratio 4.88, $p=0.02$ ). Obesity did not increase the number of minor complications $(p=0.62)$, radiographic complications $(p=0.62)$, neurological complications $(p=0.861)$, or need for revision surgery $(p=0.846)$. Obesity was not significantly correlated with OR time $(p=0.23)$, LOS $(p=0.9)$, or EBL $(p=0.98)$. Both groups experienced significant improvement over time, as measured on the ODI ( $p=0.0001)$, SF-36 ( $p=0.0001)$, and SRS $(p=$ $0.0001)$ questionnaires. However, the overall magnitude of improvement was less for obese patients (ODI, $p=0.0035$; SF-36, $p=0.0012$; SRS, $p=0.022)$. Obese patients also had a lower rate of improvement over time (SRS, $p=0.0085$; ODI, $p=0.0001 ;$ SF-36, $p=0.0001$ ).

CONCLUSIONS This study revealed that obese patients have an increased risk of complications following ASD correction. Despite these increased complications, obese patients do benefit from surgical intervention; however, their improvement in health-related quality of life (HRQL) is less than that of nonobese patients.

http://thejns.org/doi/abs/10.3171/2015.3.SPINE14743

KEY WORDS adult spinal deformity; obesity; complications; outcomes; deformity

ABBREVIATIONS ASD = adult spinal deformity; $\mathrm{BMI}=$ body mass index; $\mathrm{CCl}=$ Charlson Comorbidity Index; $\mathrm{EBL}=$ estimated blood loss; $\mathrm{HRQL}=$ health-related quality of life; IBF = interbody fusion; IRR = incidence rate ratio; LOS = length of stay; ODI = Oswestry Disability Index; OR = operating room; SF = Short Form; SRS = Scoliosis Research Society.

SUBMITTED July 31, 2014. ACCEPTED March 10, 2015.

INCLUDE WHEN CITING Published online July 31, 2015; DOI: 10.3171/2015.3.SPINE14743.

DISCLOSURE A DePuy Spine grant was received by the International Spine Study Group Foundation (ISSGF). 
I $\mathrm{N} 2011$, a publication by Finucane et al.$^{20}$ reported that the worldwide population had gained $0.4-0.5 \mathrm{~kg} / \mathrm{m}^{2}$ per decade since 1980. The obese (body mass index $\left.[\mathrm{BMI}] \geq 30 \mathrm{~kg} / \mathrm{m}^{2}\right)$ and overweight $\left(\mathrm{BMI} \geq 25 \mathrm{~kg} / \mathrm{m}^{2}\right)$ populations are increasing worldwide, with 4 of 10 adults classified as overweight or obese in 2013, according to the Global Burden of Disease Study. ${ }^{44}$ Obesity is particularly prevalent in the US, where $31.7 \%$ of adult men and $33.9 \%$ of adult women are classified as obese, accounting for a total of $13 \%$ of the global obese population; this number is expected to increase.

Adult spinal deformity (ASD) is common, and its incidence increases with age. The prevalence of ASD in the elderly population has been investigated, with Schwab et al. ${ }^{56}$ reporting rates of ASD up to $68 \%$ in patients over the age of 65 years.

Regarding ASD treatment, multiple reports have documented the superiority of surgical intervention and its potential ability to improve pain and disability, the 2 primary presenting complaints of patients with ASD. ${ }^{5,23,61,62}$ However, several authors have identified high complication rates following ASD surgery, $3,12,13,27,39,57,63,68$ with complication rates as high as $95 \% .{ }^{39}$

Several studies have examined the impact of obesity on the surgical treatment of spinal pathologies and reported increased surgical-site infections for obese patients in the context of elective lumbar spinal fusion for degenerative conditions. ${ }^{15,47}$ When looking at overall complications in the context of lumbar and cervical spine surgery, the effect of obesity is more controversial. Whereas some authors have associated obesity with increased complication rates, $, 32,33,40,58,59$ others failed to detect a link between BMI and postoperative morbidity. ${ }^{45,65,75}$ Similarly, there is no consensus on the impact of BMI on patient-reported outcomes. Several authors have reported inferior postoperative outcomes in obese patients undergoing elective degenerative lumbar, cervical, and deformity surgery, $2,34,76$ whereas others did not find that obesity negatively impacts measures of health-related quality of life (HRQL). ${ }^{15,26,53,70}$ In the spinal deformity literature, a publication by Smith et al. identified high BMI as a risk factor for worse postoperative outcomes in both older and younger ASD patients undergoing surgical treatment. ${ }^{64}$ Recently, a subgroup analysis of the Spine Patient Outcomes Research Trial $(\text { SPORT })^{51}$ concluded that obese patients with degenerative spondylolisthesis and spinal stenosis experienced similar postoperative improvement compared with nonobese patients. However, nonoperatively treated obese patients reported significantly worse outcomes than nonobese patients. The majority of the body of evidence on the impact of obesity on complications and outcomes in spinal surgery focuses on specific spinal pathologies such as elective lumbar degenerative conditions, spinal stenosis, and cervical-spine deformities. Thus, the clinical relevance of obesity in the context of ASD surgery has not been well defined.

In the present study, our objective was to investigate the impact of obesity on complications, infection, and patientreported outcomes for adults with spinal deformity undergoing surgical treatment.

\section{Methods Database}

A multiinstitutional prospective database of consecutively enrolled ASD patients was queried to obtain the data. This database included patients enrolled at 11 institutions across the US, each with a high volume of ASD surgery ( $>100$ cases performed annually). Institutional review board approval was obtained at all participating centers. Inclusion criteria for the database were: age $>18$ years, presence of spinal deformity as defined by scoliosis Cobb angle $\geq 20^{\circ}$, sagittal vertical axis (SVA) $\geq 5 \mathrm{~cm}$, pelvic tilt $\geq 25^{\circ}$, and/or thoracic kyphosis (TK) $\geq 60^{\circ}$. Exclusion criteria included spinal deformity of a neuromuscular etiology and presence of active infection or malignancy.

\section{Data Collection}

In addition to the aforementioned inclusion criteria for the database, the present study only included the patients with complete HRQL and clinical data at baseline and 2-year follow-up. Patients without recorded baseline BMI were excluded. Specifically, the following demographic and clinical data were obtained for each patient: age, sex, BMI, Charlson Comorbidity Index (CCI) score, ${ }^{9}$ smoking status, comorbidities, and surgical history. Surgical data collected included surgical approach, osteotomies performed, levels fused, operating room time (OR time), estimated blood loss (EBL), use of interbody fusion (IBF) or decompression, and length of hospital stay (LOS).

Obesity was defined as a BMI $\geq 30 \mathrm{~kg} / \mathrm{m}^{2}$ (http://www. cdc.gov/obesity/adult/defining.html). The incidence of specific complications related to the index procedure was evaluated (Table 1) and the timing of the complications was recorded. Complications were categorized as major and minor according to criteria previously reported. ${ }^{27}$ Standardized HRQL measures included the Oswestry Disability Index (ODI), ${ }^{17}$ Scoliosis Research Society-22 (SRS$22),{ }^{4}$ and Short Form-36 (SF-36) ${ }^{72}$ questionnaires and were collected at baseline and at 6 weeks, 1 year, and 2 years after surgery.

\section{Statistical Analysis}

Statistical analysis was performed using Stata v13 (StataCorp.). Univariate testing was performed using Student t-tests or chi-square tests as appropriate. The correlation of obesity and complications (major, minor, overall, radiographic, implant-related, revision surgery, neurological, and wound infection) was examined using multivariate Poisson or logistic regression modeling as appropriate. The impact of obesity on perioperative data (EBL, LOS, and OR time) was examined using multivariate linear regression. The effect of obesity on HRQL measures (SRS-22, ODI, and SF-36 scores) was determined using multivariate repeated-measures mixed models. All models accounted for potential confounders as determined by univariate analysis and expert opinion. The level of significance was $\mathrm{p}<0.05$.

\section{Results}

\section{Demographic and Operative Data}

A total of 286 patients in the database were eligible for 
TABLE 1. Complications checklist for patients undergoing ASD surgery

\begin{tabular}{|c|c|c|}
\hline Complications & Major & Minor \\
\hline Infection & $\begin{array}{l}\text { Deep } \\
\text { Pneumonia } \\
\text { Sepsis }\end{array}$ & $\begin{array}{l}\text { Superficial } \\
\text { Urinary tract infection } \\
\text { Clostridium difficile }\end{array}$ \\
\hline Implant & $\begin{array}{l}\text { Hook dislodgement } \\
\text { Interbody fracture } \\
\text { Interbody migration } \\
\text { Rod fracture } \\
\text { Rod dislodgement } \\
\text { Screw fracture }\end{array}$ & $\begin{array}{l}\text { Painful implants } \\
\text { Prominence } \\
\text { Screw malposition } \\
\text { Interbody subsidence } \\
\text { Crosslink dislodgement } \\
\text { Set screw dislodgement } \\
\text { Screw-bone interface loosening }\end{array}$ \\
\hline Neurological & $\begin{array}{l}\text { Visual deficit/blindness } \\
\text { Brachial plexus injury } \\
\text { Cerebrovascular accident/stroke } \\
\text { Spinal cord injury with incomplete deficit } \\
\text { Spinal cord injury with complete deficit } \\
\text { Nerve root injury with weakness } \\
\text { Retrograde ejaculation } \\
\text { Bowel/bladder deficit }\end{array}$ & $\begin{array}{l}\text { Neuropathy or sensory deficit } \\
\text { Pain (radiculopathy) } \\
\text { Peripheral nerve palsy } \\
\text { Delirium }\end{array}$ \\
\hline Cardiopulmonary & $\begin{array}{l}\text { Cardiac arrest } \\
\text { Pulmonary embolism } \\
\text { Respiratory arrest } \\
\text { Deep vein thrombosis } \\
\text { Congestive heart failure } \\
\text { Myocardial infarction } \\
\text { Reintubation } \\
\text { Acute respiratory distress syndrome }\end{array}$ & $\begin{array}{l}\text { Coagulopathy } \\
\text { Arrhythmia } \\
\text { Pleural effusion } \\
\text { Pneumothorax }\end{array}$ \\
\hline Gastrointestinal & $\begin{array}{l}\text { Obstruction } \\
\text { Perforation } \\
\text { Bleed requiring surgery } \\
\text { Pancreatitis requiring surgery } \\
\text { Cholecystitis requiring surgery } \\
\text { Liver failure } \\
\text { Superior mesenteric artery syndrome }\end{array}$ & $\begin{array}{l}\text { lleus } \\
\text { Bleed not requiring surgery } \\
\text { Pancreatitis not requiring surgery } \\
\text { Cholecystitis not requiring surgery }\end{array}$ \\
\hline Radiographic & $\begin{array}{l}\text { DJK (requiring surgery) } \\
\text { PJK (requiring surgery) } \\
\text { Pseudarthrosis }\end{array}$ & $\begin{array}{l}\text { DJK (not requiring surgery) } \\
\text { PJK (not requiring surgery) } \\
\text { Coronal imbalance } \\
\text { Curve decompensation } \\
\text { Heterotopic ossification } \\
\text { Sagittal imbalance } \\
\text { Adjacent-segment degeneration }\end{array}$ \\
\hline Renal & Acute renal failure requiring dialysis & Acute renal failure requiring medical intervention \\
\hline Wound problems & $\begin{array}{l}\text { Dehiscence requiring surgery } \\
\text { Hematoma/seroma with neurological deficit } \\
\text { Hematoma/seroma, no neurological deficit requiring } \\
\text { surgery } \\
\text { Incisional hernia }\end{array}$ & $\begin{array}{l}\text { Hematoma/seroma not requiring surgery } \\
\text { Hernia } \\
\text { Dehiscence not requiring surgery }\end{array}$ \\
\hline Operative & $\begin{array}{l}\text { Retained sponge/instrument } \\
\text { Wrong surgical level } \\
\text { Unintended extension of fusion } \\
\text { Vascular injury } \\
\text { Visceral injury } \\
\text { EBL }>4 \text { L }\end{array}$ & $\begin{array}{l}\text { Dural tear } \\
\text { Fixation failure (hook/screw) } \\
\text { Implant failure } \\
\text { Pedicle fracture } \\
\text { Posterior element fracture } \\
\text { Vertebral body fracture }\end{array}$ \\
\hline Vascular & Vascular injury & $\begin{array}{l}\text { Coagulopathy } \\
\text { Thrombophlebitis }\end{array}$ \\
\hline Mortality & All major & \\
\hline
\end{tabular}

DJK = distal junctional kyphosis; $\mathrm{PJK}=$ proximal junctional kyphosis. 
2-year follow-up, of which 45 patients were excluded from the study due to absence of baseline BMI data $(\mathrm{n}=17)$ and incomplete HRQL data $(\mathrm{n}=28)$. A total of 241 patients met inclusion criteria (175 nonobese, 66 obese). Baseline characteristics and perioperative data for obese and nonobese patients were compared (Table 2). Patients in the obese group had an average BMI of $36.05 \mathrm{~kg} / \mathrm{m}^{2}$ versus $24.24 \mathrm{~kg} / \mathrm{m}^{2}$ for the nonobese $(\mathrm{p}<0.0001)$. Compared with nonobese patients, the obese group was, on average, older (mean age of 59.8 years vs 53.6 years, $p=0.0038$ ), had more baseline comorbidities (mean CCI of 2.01 vs $1.19, \mathrm{p}=0.0002)$, had a higher incidence of previous spine surgery $(55.4 \%$ vs $38.1 \%, \mathrm{p}=0.017)$, and a lower incidence of smoking ( $3.1 \%$ vs $11.7 \%, \mathrm{p}=0.048)$. The 2 groups were similar with regard to sex distribution $(\mathrm{p}=0.46)$.

When comparing the magnitude of surgery between the 2 groups, obese patients had a higher incidence of major (3-column) osteotomies (27.3\% vs $15.4 \%, \mathrm{p}=0.035)$ and decompression performed $(72.7 \%$ vs $49.1 \%, \mathrm{p}=0.001)$. There were no statistically significant differences between the 2 groups with regard to the number of levels fused ( $\mathrm{p}$ $=0.8)$, the incidence of IBF $(p=0.288)$, and the surgical approach $(\mathrm{p}=0.34)($ Table 2$)$.

The differences between the 2 groups in regard to demographic data and magnitude of surgery were accounted for in all subsequent analysis through multivariate modeling.

\section{Complications}

Overall, a total of 167 patients sustained at least 1 complication (69\% overall rate, $65 \%$ for nonobese patients, and $78.8 \%$ for obese patients), with 94 patients (39\% overall rate, $33.7 \%$ for nonobese patients, and 53\% for obese patients) sustaining at least 1 major complication and 118 patients (49\% overall rate, $46.3 \%$ for nonobese patients, and $56 \%$ for obese patients) sustaining at least 1 minor complication. The impact of obesity on overall, major, and minor complications was analyzed using multivariate Poisson regression, adjusting for the following confounders: age, smoking status, comorbidities, previous spine surgery, and magnitude of surgery (osteotomy, decompression). The results showed that obese patients had a higher rate of major complications (incidence rate ratio [IRR] 1.54, $\mathrm{p}=0.021$, a trend toward higher overall complications (IRR 1.26, $\mathrm{p}$ $=0.054)$, and a similar rate of minor complications $(\mathrm{p}=$ 0.62) (Table 3).

\section{Individual Complications}

Based on the entire study population, the infection rate was $5.4 \%$ (3.4\% nonobese patients, $10.6 \%$ obese patients), and $20.7 \%$ of patients (18.8\% nonobese patients, $25.75 \%$ obese patients) sustained at least 1 radiographic complication, $16 \%$ of patients (14.3\% nonobese patients, $21.2 \%$ obese patients) had at least 1 implant-related complication, and $20.3 \%$ of patients (19.4\% nonobese patients, $22.7 \%$ obese patients) had at least 1 neurological complication. The overall 2-year surgical revision rate was $20.7 \%$ (20\% nonobese patients, $22.7 \%$ obese patients). The effect of obesity on specific types of complications was assessed using multivariate Poisson and logistic regression to adjust for potential confounders. This analysis demonstrated that obesity was an independent risk factor for postopera-
TABLE 2. Comparison of baseline demographic data and surgical magnitude between obese and nonobese patients

\begin{tabular}{lcll}
\hline \multicolumn{1}{c}{ Variable } & Nonobese & Obese & $\mathrm{p}$ Value \\
\hline No. of patients & 175 & 66 & \\
\hline Baseline patient factors & & & \\
\hline $\mathrm{BMI}\left(\mathrm{kg} / \mathrm{m}^{2}\right)$ & 24.2 & 36.1 & $<0.0001$ \\
\hline Sex $(\mathrm{F})$ & $86.7 \%$ & $83.1 \%$ & 0.46 \\
\hline Age $(\mathrm{yrs})$ & 53.6 & 59.8 & 0.0038 \\
\hline Previous spine surgery & $38.1 \%$ & $55.4 \%$ & 0.017 \\
\hline CCl & 1.19 & 2.01 & 0.0002 \\
\hline Smoker & $11.7 \%$ & $3.1 \%$ & 0.048 \\
\hline Magnitude of surgery & & & \\
\hline Major osteotomy & $15.4 \%$ & $27.3 \%$ & 0.035 \\
\hline Levels & 9.54 & 9.42 & 0.8 \\
\hline Posterior-only approach & $61.1 \%$ & $62.1 \%$ & 0.34 \\
\hline IBF & $51.4 \%$ & $59.1 \%$ & 0.288 \\
\hline Decompression & $49.1 \%$ & $72.7 \%$ & 0.001 \\
\hline
\end{tabular}

tive wound infection (odds ratio 4.88, $\mathrm{p}=0.02$ ). However, obesity was not associated with a significantly increased risk of neurological complications $(\mathrm{p}=0.88)$, revision surgery $(\mathrm{p}=0.84)$, or radiographic complications $(\mathrm{p}=0.62)$. Absolute weight (odds ratio 1.16, $\mathrm{p}=0.064$ ), rather than BMI $(p=0.80)$, showed a trend toward an increased risk of implant-related complications (Table 4).

\section{Operative Data}

To study the impact of obesity on operative data, multivariate linear regression modeling was performed, accounting for potential confounders. Results revealed that obesity did not significantly increase average LOS $(\mathrm{p}=$ $0.9)$, average EBL $(\mathrm{p}=0.98)$, or average OR time $(\mathrm{p}=0.23)$ (Table 5).

\section{Patient-Reported Outcomes}

The impact of obesity on HRQL was assessed using multivariate repeated-measures mixed models. Models accounted for age, comorbidities, magnitude of surgery, and major complications including revision surgeries. These analyses demonstrated that both obese and nonobese patients experienced significant improvement in their HRQL over time, as measured on the ODI ( $p=0.0001)$, SF-36 ( $p$ $=0.0001)$, and SRS $(\mathrm{p}=0.0001)$ questionnaires. However, the overall magnitude of improvement was less for obese patients (ODI, $\mathrm{p}=0.0035$; SF-36, $\mathrm{p}=0.0012$; SRS, $\mathrm{p}=$ 0.022). Obese patients also had a lower rate of improvement over time (SRS, $\mathrm{p}=0.0085$; ODI, $\mathrm{p}=0.0001$; SF-36, $\mathrm{p}=0.0001)($ Table 6, Figs. 1-3).

\section{Discussion}

\section{Patient Demographic Data}

Twenty-seven percent of patients included in this study were obese, with a mean age of about 60 years, which is consistent with obesity rates in the general population as defined by the Global Burden of Disease study ${ }^{44}$ and the 
TABLE 3. Multivariate Poisson regression results showing the IRR of overall, major, and minor complications in obese patients*

\begin{tabular}{ccc}
\hline Complications, 2 Yrs & IRR & p Value \\
\hline Overall & 1.26 & 0.054 \\
\hline Major & 1.54 & 0.021 \\
\hline Minor & 1.08 & 0.62 \\
\hline
\end{tabular}

* Complications in patients with BMI $\geq 30$. All models accounted for age, smoking status, comorbidities, previous spine surgery, and magnitude of surgery.

worldwide comparative analyses of long-term trends of BMI. ${ }^{20}$ Obese patients reported higher rates of comorbidities (CCI), consistent with a report from Ezzati et al. and the WHO. 16,73

In 2005, obesity overtook smoking as the most common preventable cause of illness in the US. ${ }^{42}$ Notably, these 2 problems are inversely related, with several studies associating obesity with smoking cessation, ${ }^{19,28,31}$ and weight gain being one of the main concerns for individuals who are considering smoking cessation. ${ }^{71}$ In the present study, obese patients also reported a lower incidence of smoking, which is consistent with previous reports. In the present study, obese patients were more likely to require a decompression, which is consistent with previous studies that suggested obesity is a risk factor for spinal stenosis..$^{21,34,67}$

\section{Methodology of Complications Acquisition}

The complications rate in spinal surgery literature varies widely. Many factors may contribute to these variations, such as the characteristics of the studied cohort, the type of surgery performed, and the length of the follow-up. Nasser et al., ${ }^{43}$ in a systematic review of the spinal surgery literature, reported that the rate of complications for thoracolumbar surgeries ranged from $<1 \%$ to $70 \%$. Notably, retrospective studies have a tendency to underestimate the incidence of complications. ${ }^{7,43}$

In the present study, all sites prospectively collected complications based on a standardized data-collection form (Table 1). This methodology helped to facilitate higher accuracy and better estimation of the complications. Comparison with published works that have similar methodology, patient population, and follow-up shows that the overall, major, and minor complication rates in the present study are consistent. . $^{10,11,22,60,66,68}$

\section{Obesity Versus Complications, Perioperative Metrics, and Clinical Outcomes}

This study identified obesity as an independent risk factor for increased postoperative complications, even after adjusting for confounders such as comorbidities and magnitude of surgery. This is consistent with the results of other works, including a recent meta-analysis of spine surgery patients by Jiang et al..$^{12,32,47}$ Their study demonstrated that obesity is an independent risk factor for surgical-site infections. These findings are consistent with the literature. ${ }^{1,8,15,35,40,49,51,59}$ In a recent study specific to ASD, Pull ter Gunne and Cohen ${ }^{48}$ identified risk factors for wound infections in the ASD population and found obesity to be associated with both deep and superficial wound infec-
TABLE 4. Multivariate Poisson and logistic regression showing the IRR and odds ratio of specific complications in obese patients*

\begin{tabular}{lcl}
\hline Complications, 2 Yrs & IRR/Odds Ratio & p Value \\
\hline Neurological & 0.03 & 0.881 \\
\hline Radiographic & -0.139 & 0.626 \\
\hline Revision surgery & 1.07 & 0.846 \\
\hline Infection & 4.88 & 0.02 \\
\hline Implant (BMI) & 0.08 & 0.804 \\
\hline Implant (weight) & 1.16 & 0.064 \\
\hline
\end{tabular}

* All models accounted for age, smoking status, comorbidities, previous spine surgery, and magnitude of surgery. Radiographic complications, implantrelated complications, and revision surgeries also accounted for rod size and rod material.

tions. Our results are consistent with these findings and contribute to the small body of evidence on this subject. In a publication looking at lumbar fusion surgery, Mehta et $\mathrm{al}^{41}$ found that the thickness of subcutaneous fat and the skin-to-lamina distance are risk factors for surgicalsite infections. This is probably due to the fact that thicker subcutaneous fat may require further retraction, leading to increased dead space postoperatively, which in turn increases the risk of infection. Further studies should specifically address the relationship between thickness of subcutaneous fat and surgical-site infection in the context of long fusions for ASD.

In the current study, obesity was not associated with radiographic or implant-related complications. This finding is consistent with recent work by $\mathrm{Fu}$ et al. ${ }^{24}$ Weight itself, rather than BMI, showed a trend toward increased implant-related complications. This suggests that there may be an absolute weight threshold that puts more stress on the implants, leading to higher risk of implant failure due to stress fatigue. For example, a short patient classified as obese based on BMI may not meet this weight threshold. Conversely, a very tall patient may not be classified as obese based on BMI but may still have a weight high enough to put significant stress on the implants, leading to increased risk of implant-related complications.

With regard to perioperative metrics, our data suggest that obesity is not an independent factor for increased OR time, EBL, or LOS. These findings are contrary to the results of studies based on the degenerative spine population. ${ }^{6,33,40,58,70,77}$ Our findings may be explained by the fact that ASD surgery is generally of a greater magnitude than surgery for degenerative spinal conditions, often requiring longer fusion levels and osteotomies. For example, adult

TABLE 5. Multivariate linear regression results looking at EBL, OR time, and LOS*

\begin{tabular}{lcc}
\hline 2-Yr Only & Coefficient & p Value \\
\hline LOS & 0.05 & 0.9 \\
\hline EBL & 5.99 & 0.98 \\
\hline OR time & 23.2 & 0.23 \\
\hline
\end{tabular}

* All models accounted for age, smoking status, comorbidities, previous spine surgery, and magnitude of surgery. 
TABLE 6. Multivariate repeated-measures mixed modeling looking at the impact of obesity on HRQL

\begin{tabular}{|c|c|c|c|c|c|}
\hline \multirow[b]{2}{*}{ Instrument } & \multicolumn{4}{|c|}{ Group \& Score } & \multirow[b]{2}{*}{$p$ Value } \\
\hline & Nonobese & SE & Obese & SE & \\
\hline \multicolumn{6}{|c|}{ SF-36 physical } \\
\hline Baseline & 33.40 & 0.58 & 28.84 & 0.94 & \multirow{4}{*}{$\begin{array}{l}\text { Group: } 0.0012 \\
\text { Time: } 0.00001 \\
G^{*} \text { T: } 0.00001\end{array}$} \\
\hline 6 wks & 28.72 & 0.78 & 30.26 & 1.06 & \\
\hline $1 \mathrm{yr}$ & 40.84 & 0.67 & 38.92 & 1.13 & \\
\hline $2 \mathrm{yrs}$ & 42.76 & 0.71 & 36.52 & 1.14 & \\
\hline \multicolumn{6}{|l|}{ ODI } \\
\hline Baseline & 40.32 & 1.09 & 49.29 & 1.77 & \multirow{4}{*}{$\begin{array}{l}\text { Group: } 0.0035 \\
\text { Time: } 0.00001 \\
G^{*} T: 0.0001\end{array}$} \\
\hline 6 wks & 47.15 & 1.27 & 46.81 & 1.95 & \\
\hline $1 \mathrm{yr}$ & 26.68 & 1.24 & 29.74 & 2.09 & \\
\hline 2 yrs & 24.18 & 1.29 & 33.19 & 2.11 & \\
\hline \multicolumn{6}{|l|}{ SRS-22 } \\
\hline Baseline & 2.88 & 0.042 & 2.67 & 0.069 & \multirow{4}{*}{$\begin{array}{l}\text { Group: } 0.022 \\
\text { Time: } 0.00001 \\
G^{*} T: 0.0085\end{array}$} \\
\hline 6 wks & 3.06 & 0.048 & 3.07 & 0.074 & \\
\hline $1 \mathrm{yr}$ & 3.71 & 0.047 & 3.57 & 0.078 & \\
\hline $2 \mathrm{yrs}$ & 3.76 & 0.050 & 3.45 & 0.080 & \\
\hline
\end{tabular}

* Models accounted for age, comorbidities, magnitude of surgery, and major complications including revision surgeries.

deformity procedures typically involve relatively longer and more varied OR times and LOS, which may make detection of the potential impact of obesity on these parameters more difficult and perhaps relatively less significant. However, it is possible that our study may have been underpowered to detect a small difference in these metrics. Further studies with a larger surgical ASD patient population are required to confirm these findings.

In the present study, obese patients had significantly worse HRQL scores prior to the surgical treatment. This finding is consistent with previous reports suggesting that obesity can contribute to back pain, sciatica, disc-height reduction and degeneration, and eventually worse quality of life and disability. ${ }^{14,29,30,36-38,52,54,55,69,74}$ This added baseline compromise did not preclude obese patients from benefiting from surgery. After adjusting for confounders, including the incidence of major complications, our results show

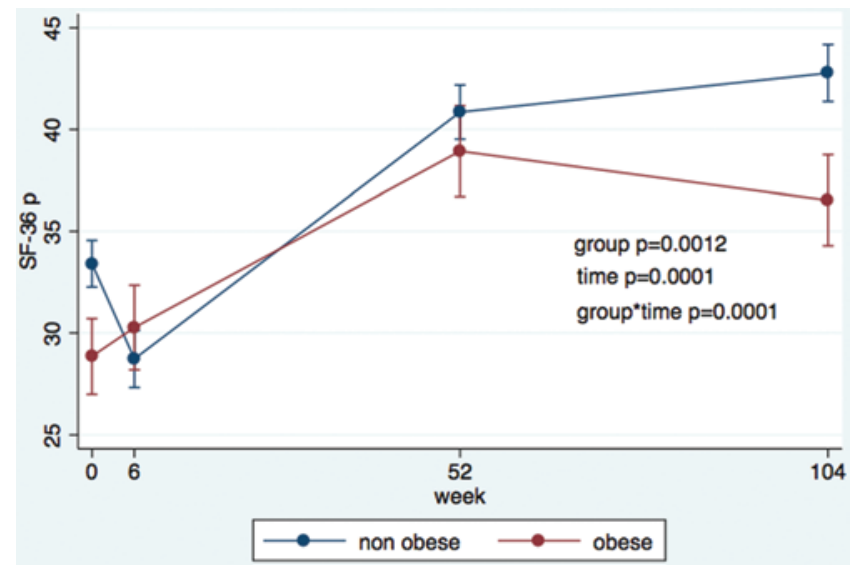

FIG. 1. Results of multivariate repeated-measures mixed models show the difference between SF-36 physical scores in obese versus nonobese groups at baseline and at 6-week, 1-year, and 2-year follow-up. Figure is available in color online only. that obese patients do improve after ASD surgery, although not to the same extent as nonobese patients. This was true for all 3 patient-reported outcomes that were assessed (SF36 physical, ODI, and SRS scores). Previous studies for spinal conditions other than adult deformity have also identified lower rates of improvement in HRQL scores for obese patients. ${ }^{11,18,34,76}$ However, a recent study by Rihn et al. ${ }^{50}$ that assessed a subgroup analysis of the Spine Patient Outcomes Research Trial (SPORT) showed that, in the context of spinal stenosis and degenerative spondylolisthesis, obese patients experience postoperative improvements similar to those of nonobese patients, whereas they do significantly worse with nonoperative treatment, resulting in a larger treatment effect of surgery in obese patients. Our study did not examine how obese patients benefit from nonoperative treatment, and further studies should look at this question in the ASD population.

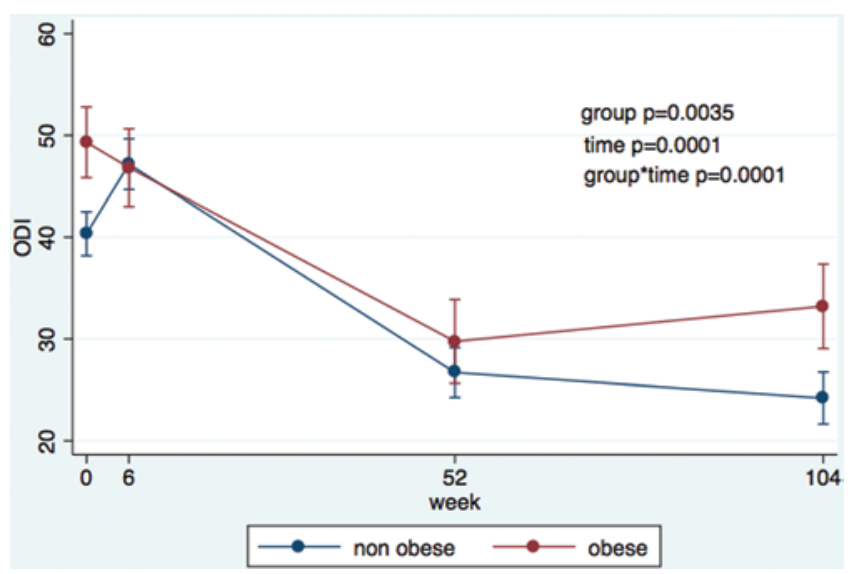

FIG. 2. Results of multivariate repeated-measures mixed models show the difference between ODI scores in obese versus nonobese groups at baseline and at 6 -week, 1 -year, and 2-year follow-up. Figure is available in color online only. 


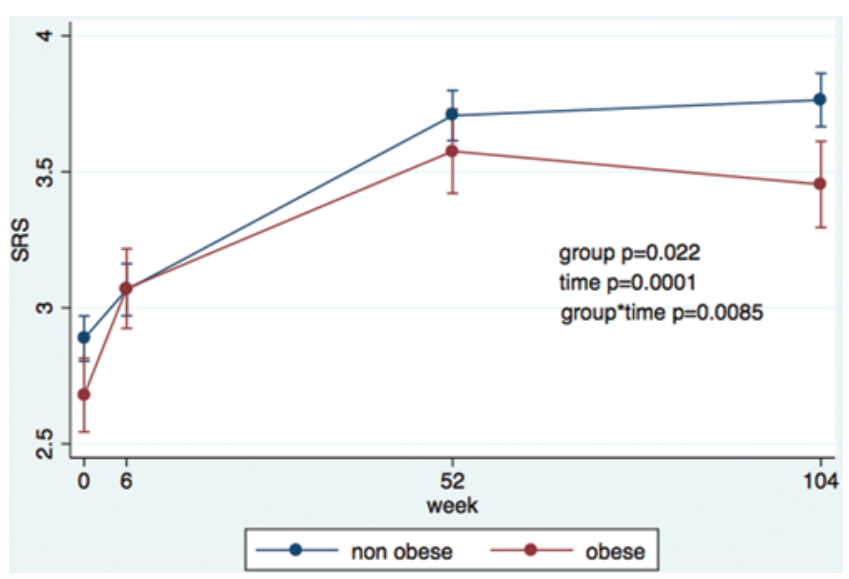

FIG. 3. Results of multivariate repeated-measures mixed models show the difference between SRS scores in obese versus nonobese groups at baseline and at 6-week, 1-year, and 2-year follow-up. Figure is available in color online only.

\section{Obesity as a Risk Factor for Reoperation}

After adjusting for age, smoking status, comorbidities, previous spine surgery, and magnitude of surgery, obesity was not a significant risk factor for reoperation in the current study of ASD patients. This is contrary to the literature in the elective lumbar surgery population,,$^{25,32}$ but can be explained by the reality that ASD has an overall high reoperation rate (20.3\% in our series). Furthermore, ASD revisions are often due to implant failure, pseudarthrosis, or proximal junctional kyphosis,$^{46}$ complications that may be heightened by the biomechanical impact of excess weight.

\section{Limitations of the Study}

This study has several limitations. Due to its observational nature, the obese and nonobese groups were different in regard to baseline patient characteristics and magnitude of surgery. Although we accounted for these variables through multivariate analysis, it is possible that there are some unmeasured sources of bias that we were unable to adjust for. Moreover, due to the relatively small sample size, it is possible that our study was underpowered to detect smaller differences in some of our outcome measures, such as EBL and OR time. Additionally, it would have been interesting to examine if the super-obese patients (obesity Class III) are at even greater risk of postoperative complications. However, we were not able to do any subgroup analysis due to our sample size. Finally, although it would be interesting to follow these patients for a longer period of time to determine the long-term impact of obesity after ASD surgery, our follow-up period was limited to 2 years.

\section{Conclusions}

This study found that obese patients are a higher-risk group than the general ASD population and quantifies that risk. Despite increased complications, obese patients do benefit from ASD surgery. However, their improvement in HRQL measures appears to be less than that of nonobese patients. These findings may prove useful as part of the preoperative discussion with obese patients with ASD who are considering surgical intervention.

\section{References}

1. Abdallah DY, Jadaan MM, McCabe JP: Body mass index and risk of surgical site infection following spine surgery: a metaanalysis. Eur Spine J 22:2800-2809, 2013

2. Auffinger B, Lam S, Kraninger J, Shen J, Roitberg BZ: The impact of obesity on surgeon ratings and patient-reported outcome measures after degenerative cervical spine disease surgery. World Neurosurg:1-8, 2013

3. Bhagat S, Vozar V, Lutchman L, Crawford RJ, Rai AS: Morbidity and mortality in adult spinal deformity surgery: Norwich Spinal Unit experience. Eur Spine J 22 (Suppl 1):S42-S46, 2013

4. Bridwell KH, Cats-Baril W, Harrast J, Berven S, Glassman S, Farcy JP, et al: The validity of the SRS-22 instrument in an adult spinal deformity population compared with the Oswestry and SF-12: a study of response distribution, concurrent validity, internal consistency, and reliability. Spine (Phila Pa 1976) 30:455-461, 2005

5. Bridwell KH, Glassman S, Horton W, Shaffrey C, Schwab F, Zebala LP, et al: Does treatment (nonoperative and operative) improve the two-year quality of life in patients with adult symptomatic lumbar scoliosis: a prospective multicenter evidence-based medicine study. Spine (Phila Pa 1976) 34:2171-2178, 2009

6. Buerba RA, Fu MC, Gruskay JA, Long WD III, Grauer JN: Obese Class III patients at significantly greater risk of multiple complications after lumbar surgery: an analysis of 10,387 patients in the ACS NSQIP database. Spine J 14:2008-2018, 2014

7. Campbell PG, Malone J, Yadla S, Chitale R, Nasser R, Maltenfort MG, et al: Comparison of ICD-9-based, retrospective, and prospective assessments of perioperative complications: assessment of accuracy in reporting. J Neurosurg Spine 14:16-22, 2011

8. Chaichana KL, Bydon M, Santiago-Dieppa DR, Hwang L, McLoughlin G, Sciubba DM, et al: Risk of infection following posterior instrumented lumbar fusion for degenerative spine disease in 817 consecutive cases. J Neurosurg Spine 20:45-52, 2014

9. Charlson ME, Pompei P, Ales KL, MacKenzie CR: A new method of classifying prognostic comorbidity in longitudinal studies: development and validation. J Chronic Dis 40:373383, 1987

10. Charosky S, Guigui P, Blamoutier A, Roussouly P, Chopin $\mathrm{D}$ : Complications and risk factors of primary adult scoliosis surgery: a multicenter study of 306 patients. Spine (Phila Pa 1976) 37:693-700, 2012

11. Cho SK, Bridwell KH, Lenke LG, Cho W, Zebala LP, Pahys JM, et al: Comparative analysis of clinical outcome and complications in primary versus revision adult scoliosis surgery. Spine (Phila Pa 1976) 37:393-401, 2012

12. Cho SK, Bridwell KH, Lenke LG, Yi JS, Pahys JM, Zebala LP, et al: Major complications in revision adult deformity surgery: risk factors and clinical outcomes with 2- to 7-year follow-up. Spine (Phila Pa 1976) 37:489-500, 2012

13. DeWald CJ, Stanley T: Instrumentation-related complications of multilevel fusions for adult spinal deformity patients over age 65: surgical considerations and treatment options in patients with poor bone quality. Spine (Phila Pa 1976) 31 (19 Suppl):S144-S151, 2006

14. Deyo RA, Bass JE: Lifestyle and low-back pain. The influence of smoking and obesity. Spine (Phila Pa 1976) 14:501506,1989

15. Djurasovic M, Bratcher KR, Glassman SD, Dimar JR, Carreon LY: The effect of obesity on clinical outcomes after lumbar fusion. Spine (Phila Pa 1976) 33:1789-1792, 2008 
16. Ezzati M, Lopez AD, Rodgers A, Vander Hoorn S, Murray CJL: Selected major risk factors and global and regional burden of disease. Lancet 360:1347-1360, 2002

17. Fairbank JC, Pynsent PB: The Oswestry Disability Index. Spine (Phila Pa 1976) 25:2940-2952, discussion 2952, 2000

18. Fanuele JC, Abdu WA, Hanscom B, Weinstein JN: Association between obesity and functional status in patients with spine disease. Spine (Phila Pa 1976) 27:306-312, 2002

19. Ferguson S, Al-Rehany L, Tang C, Gougeon L, Warwick K, Madill J: Self-reported causes of weight gain: among prebariatric surgery patients. Can J Diet Pract Res 74:189-192, 2013

20. Finucane MM, Stevens GA, Cowan MJ, Danaei G, Lin JK, Paciorek CJ, et al: National, regional, and global trends in body-mass index since 1980: systematic analysis of health examination surveys and epidemiological studies with 960 country-years and 9.1 million participants. Lancet 377:557567,2011

21. Foulongne E, Derrey S, Ould Slimane M, Levèque S, Tobenas AC, Dujardin F, et al: Lumbar spinal stenosis: which predictive factors of favorable functional results after decompressive laminectomy? Neurochirurgie 59:23-29, 2013

22. Fritzell $P$, Hägg $O$, Wessberg $P$, Nordwall A: Chronic low back pain and fusion: a comparison of three surgical techniques: a prospective multicenter randomized study from the Swedish lumbar spine study group. Spine (Phila Pa 1976) 27:1131-1141, 2002

23. Fu KMG, Bess S, Shaffrey CI, Smith JS, Lafage V, Schwab FJ, et al: Patients with adult spinal deformity treated operatively report greater baseline pain and disability than patients treated nonoperatively; however, deformities differ between age groups. Spine (Phila Pa 1976) 39:1401-1407, 2014

24. Fu L, Chang MS, Crandall DG, Revella J: Does obesity affect surgical outcomes in degenerative scoliosis? Spine (Phila Pa 1976) 39:2049-2055, 2014

25. Gaudelli C, Thomas K: Obesity and early reoperation rate after elective lumbar spine surgery: a population-based study. Evid Based Spine Care J 3:11-16, 2012

26. Gepstein R, Shabat S, Arinzon ZH, Berner Y, Catz A, Folman Y: Does obesity affect the results of lumbar decompressive spinal surgery in the elderly? Clin Orthop Relat Res (426):138-144, 2004

27. Glassman SD, Hamill CL, Bridwell KH, Schwab FJ, Dimar JR, Lowe TG: The impact of perioperative complications on clinical outcome in adult deformity surgery. Spine (Phila Pa 1976) 32:2764-2770, 2007

28. Grandi SM, Filion KB, Gervais A, Joseph L, O'Loughlin J, Paradis G, et al: Weight change in patients attempting to quit smoking post-myocardial infarction. Am J Med 127:641649, 649.e1, 2014

29. Häuser W, Schmutzer G, Brähler E, Schiltenwolf M, Hilbert A: The impact of body weight and depression on low back pain in a representative population sample. Pain Med 15:1316-1327, 2014

30. Heuch I, Heuch I, Hagen K, Zwart JA: Body mass index as a risk factor for developing chronic low back pain: a follow-up in the Nord-Trøndelag Health Study. Spine (Phila Pa 1976) 38:133-139, 2013

31. Issa JS, Santos PCJL, Vieira LP, Abe TO, Kuperszmidt CS, Nakasato M, et al: Smoking cessation and weight gain in patients with cardiovascular disease or risk factor. Int J Cardiol 172:485-487, 2014

32. Jiang J, Teng Y, Fan Z, Khan S, Xia Y: Does obesity affect the surgical outcome and complication rates of spinal surgery? A meta-analysis. Clin Orthop Relat Res 472:968-975, 2014

33. Kalanithi PA, Arrigo R, Boakye M: Morbid obesity increases cost and complication rates in spinal arthrodesis. Spine (Phila Pa 1976) 37:982-988, 2012

34. Knutsson B, Michaëlsson K, Sandén B: Obesity is associated with inferior results after surgery for lumbar spinal stenosis: a study of 2633 patients from the Swedish spine register.

Spine (Phila Pa 1976) 38:435-441, 2013

35. Kurtz SM, Lau E, Ong KL, Carreon L, Watson H, Albert T, et al: Infection risk for primary and revision instrumented lumbar spine fusion in the Medicare population. J Neurosurg Spine 17:342-347, 2012

36. Leboeuf-Yde C: Body weight and low back pain. A systematic literature review of 56 journal articles reporting on 65 epidemiologic studies. Spine (Phila Pa 1976) 25:226-237, 2000

37. Lidar Z, Behrbalk E, Regev GJ, Salame K, Keynan O, Schweiger C, et al: Intervertebral disc height changes after weight reduction in morbidly obese patients and its effect on quality of life and radicular and low back pain. Spine (Phila Pa 1976) 37:1947-1952, 2012

38. Liuke M, Solovieva S, Lamminen A, Luoma K, Leino-Arjas $\mathrm{P}$, Luukkonen R, et al: Disc degeneration of the lumbar spine in relation to overweight. Int J Obes (Lond) 29:903-908, 2005

39. Lonergan T, Place H, Taylor P: Acute complications following adult spinal deformity surgery in patients aged 70 years and older. J Spinal Disord Tech [epub ahead of print], 2012

40. Marquez-Lara A, Nandyala SV, Sankaranarayanan S, Noureldin M, Singh K, Sankaaranrayanan S: Body mass index as a predictor of complications and mortality after lumbar spine surgery. Spine (Phila Pa 1976) 39:798-804, 2014

41. Mehta AI, Babu R, Karikari IO, Grunch B, Agarwal VJ, Owens TR, et al: 2012 Young Investigator Award winner: The distribution of body mass as a significant risk factor for lumbar spinal fusion postoperative infections. Spine (Phila Pa 1976) 37:1652-1656, 2012

42. Mokdad AH, Marks JS, Stroup DF, Gerberding JL: Actual causes of death in the United States, 2000. JAMA 291:12381245,2004

43. Nasser R, Yadla S, Maltenfort MG, Harrop JS, Anderson DG, Vaccaro AR, et al: Complications in spine surgery. J Neurosurg Spine 13:144-157, 2010

44. Ng M, Fleming T, Robinson M, Thomson B, Graetz N, Margono $\mathrm{C}$, et al: Global, regional, and national prevalence of overweight and obesity in children and adults during 19802013: a systematic analysis for the Global Burden of Disease Study 2013. Lancet 384:766-781, 2014

45. Park P, Upadhyaya C, Garton HJ, Foley KT: The impact of minimally invasive spine surgery on perioperative complications in overweight or obese patients. Neurosurgery 62:693699, 2008

46. Passias PG, Yang S, Soroceanu A, Smith SJ, Shaffrey C, Boachie-Adjei O, et al: Predictors of revision surgery in adult spinal deformity and impact on patient-reported outcomes and satisfaction: two-year follow up, in 21st International Meeting on Advanced Spine Techniques Final Program. Milwaukee: Scoliosis Research Society, 2014, Abstract \#36

47. Patel N, Bagan B, Vadera S, Maltenfort MG, Deutsch H, Vaccaro AR, et al: Obesity and spine surgery: relation to perioperative complications. J Neurosurg Spine 6:291-297, 2007

48. Pull ter Gunne AF, Cohen DB: Incidence, prevalence, and analysis of risk factors for surgical site infection following adult spinal surgery. Spine (Phila Pa 1976) 34:1422-1428, 2009

49. Pull ter Gunne AF, van Laarhoven CJHM, Cohen DB: Incidence of surgical site infection following adult spinal deformity surgery: an analysis of patient risk. Eur Spine J 19:982-988, 2010

50. Rihn JA, Kurd M, Hilibrand AS, Lurie J, Zhao W, Albert $T$, et al: The influence of obesity on the outcome of treatment of lumbar disc herniation: analysis of the Spine Patient Outcomes Research Trial (SPORT). J Bone Joint Surg Am 95:1-8, 2013

51. Rihn JA, Radcliff K, Hilibrand AS, Anderson DT, Zhao W, 
Lurie J, et al: Does obesity affect outcomes of treatment for lumbar stenosis and degenerative spondylolisthesis? Analysis of the Spine Patient Outcomes Research Trial (SPORT). Spine (Phila Pa 1976) 37:1933-1946, 2012

52. Rissanen A, Heliövaara M, Knekt P, Reunanen A, Aromaa A, Maatela J: Risk of disability and mortality due to overweight in a Finnish population. BMJ 301:835-837, 1990

53. Rosen DS, Ferguson SD, Ogden AT, Huo D, Fessler RG: Obesity and self-reported outcome after minimally invasive lumbar spinal fusion surgery. Neurosurgery 63:956-960, 2008

54. Samartzis D, Karppinen J, Chan D, Luk KDK, Cheung KMC: The association of lumbar intervertebral disc degeneration on magnetic resonance imaging with body mass index in overweight and obese adults: a population-based study. Arthritis Rheum 64:1488-1496, 2012

55. Samartzis D, Karppinen J, Cheung JPY, Lotz J: Disk degeneration and low back pain: are they fat-related conditions? Global Spine J 3:133-144, 2013

56. Schwab F, Dubey A, Gamez L, El Fegoun AB, Hwang K, Pagala M, Farcy JP: Adult scoliosis: prevalence, SF-36, and nutritional parameters in an elderly volunteer population. Spine (Phila Pa 1976) 30:1082-1085, 2005

57. Schwab FJ, Hawkinson N, Lafage V, Smith JS, Hart R, Mundis G, et al: Risk factors for major peri-operative complications in adult spinal deformity surgery: a multi-center review of 953 consecutive patients. Eur Spine J 21:2603-2610, 2012

58. Seicean A, Alan N, Seicean S, Worwag M, Neuhauser D, Benzel EC, et al: Impact of increased body mass index on outcomes of elective spinal surgery. Spine (Phila Pa 1976) 39:1520-1530, 2014

59. Shamji MF, Parker S, Cook C, Pietrobon R, Brown C, Isaacs RE: Impact of body habitus on perioperative morbidity associated with fusion of the thoracolumbar and lumbar spine. Neurosurgery 65:490-498, 2009

60. Simmons ED Jr, Kowalski JM, Simmons EH: The results of surgical treatment for adult scoliosis. Spine (Phila Pa 1976) 18:718-724, 1993

61. Smith JS, Kasliwal MK, Crawford AH, Shaffrey CI: Outcomes, expectations, and complications overview for the surgical treatment of adult and pediatric spinal deformity. Spine Deform [epub ahead of print], 2012

62. Smith JS, Shaffrey CI, Berven S, Glassman S, Hamill C, Horton W, et al: Improvement of back pain with operative and nonoperative treatment in adults with scoliosis. Neurosurgery 65:86-94, 2009

63. Smith JS, Shaffrey CI, Berven S, Glassman S, Hamill C, Horton W, et al: Operative versus nonoperative treatment of leg pain in adults with scoliosis: a retrospective review of a prospective multicenter database with two-year follow-up. Spine (Phila Pa 1976) 34:1693-1698, 2009

64. Smith JS, Shaffrey CI, Glassman SD, Carreon LY, Schwab FJ, Lafage V, et al: Clinical and radiographic parameters that distinguish between the best and worst outcomes of scoliosis surgery for adults. Eur Spine J 22:402-410, 2013

65. Srinivasan D, La Marca F, Than KD, Patel RD, Park P: Perioperative characteristics and complications in obese patients undergoing anterior cervical fusion surgery. J Clin Neurosci 21:1159-1162, 2014

66. Swank S, Lonstein JE, Moe JH, Winter RB, Bradford DS: Surgical treatment of adult scoliosis. A review of two hundred and twenty-two cases. J Bone Joint Surg Am 63:268287, 1981

67. Tomkins-Lane CC, Lafave LMZ, Parnell JA, Krishnamurthy A, Rempel J, Macedo LG, et al: The spinal stenosis pedometer and nutrition lifestyle intervention (SSPANLI) randomized controlled trial protocol. BMC Musculoskelet Disord 14:322, 2013
68. Uribe JS, Deukmedjian AR, Mummaneni PV, Fu KMG, Mundis GM Jr, Okonkwo DO, et al: Complications in adult spinal deformity surgery: an analysis of minimally invasive, hybrid, and open surgical techniques. Neurosurg Focus 36(5):E15, 2014

69. Urquhart DM, Kurniadi I, Triangto K, Wang Y, Wluka AE, O'Sullivan R, et al: Obesity is associated with reduced disc height in the lumbar spine but not at the lumbosacral junction. Spine (Phila Pa 1976) 39:E962-E966, 2014

70. Vaidya R, Carp J, Bartol S, Ouellette N, Lee S, Sethi A: Lumbar spine fusion in obese and morbidly obese patients. Spine (Phila Pa 1976) 34:495-500, 2009

71. Veldheer S, Yingst J, Foulds G, Hrabovsky S, Berg A, Sciamanna C, et al: Once bitten, twice shy: concern about gaining weight after smoking cessation and its association with seeking treatment. Int J Clin Pract 68:388-395, 2014

72. Ware JE Jr, Sherbourne CD: The MOS 36-item short-form health survey (SF-36). I. Conceptual framework and item selection. Med Care 30:473-483, 1992

73. World Health Organization (WHO): Obesity: preventing and managing the global epidemic. Report of a WHO consultation. World Health Organ Tech Rep Ser 894:i-xii, 1-253, 2000

74. Wright D, Barrow S, Fisher AD, Horsley SD, Jayson MI: Influence of physical, psychological and behavioural factors on consultations for back pain. Br J Rheumatol 34:156-161, 1995

75. Yadla S, Malone J, Campbell PG, Maltenfort MG, Harrop JS, Sharan AD, et al: Obesity and spine surgery: reassessment based on a prospective evaluation of perioperative complications in elective degenerative thoracolumbar procedures. Spine J 10:581-587, 2010

76. Yagi M, Patel R, Boachie-Adjei O: Complications and unfavorable clinical outcomes in obese and overweight patients treated for adult lumbar or thoracolumbar scoliosis with combined anterior/posterior surgery. J Spinal Disord Tech [epub ahead of print], 2013

77. Zheng F, Cammisa FP Jr, Sandhu HS, Girardi FP, Khan SN: Factors predicting hospital stay, operative time, blood loss, and transfusion in patients undergoing revision posterior lumbar spine decompression, fusion, and segmental instrumentation. Spine (Phila Pa 1976) 27:818-824, 2002

\section{Author Contributions}

Conception and design: Lafage, Soroceanu, Burton, Smith, Hostin, Shaffrey, Boachie-Adjei, Mundis, Ames, Errico, Bess, Gupta, Hart, Schwab. Acquisition of data: Lafage, Diebo, Smith, Hostin, Shaffrey, Boachie-Adjei, Mundis, Ames, Errico, Bess, Gupta, Hart, Schwab. Analysis and interpretation of data: Lafage, Soroceanu, Burton, Smith, Hostin, Shaffrey, Boachie-Adjei, Mundis, Ames, Errico, Bess, Gupta, Hart, Schwab. Drafting the article: Lafage, Soroceanu, Burton, Diebo. Critically revising the article: Lafage, Smith, Hostin, Shaffrey, Boachie-Adjei, Mundis, Ames, Errico, Bess, Gupta, Hart, Schwab. Statistical analysis: Lafage, Soroceanu, Burton. Administrative/technical/material support: Lafage, Soroceanu, Burton, Diebo. Study supervision: Lafage, Soroceanu, Burton, Smith, Hostin, Shaffrey, BoachieAdjei, Mundis, Ames, Errico, Bess, Gupta, Hart, Schwab.

\section{Correspondence}

Virginie Lafage, Orthopaedic Surgery, NYU Hospital for Joint Diseases, 306 East 15th St., New York, NY 10003. E-mail: virginie.lafage@gmail.com. 